\title{
High-Density Freestanding Graphene/Carbide-Derived Carbon Film Electrodes for Electrochemical Capacitors
}

\author{
Mohamed Alhabeb, Majid Beidaghi, Katherine L. Van Aken, Boris Dyatkin, \\ Yury Gogotsi* \\ A.J. Drexel Nanomaterials Institute and Department of Materials Science and \\ Engineering, Drexel University \\ 3141 Chestnut St, Philadelphia, PA 19104, USA
}

\begin{abstract}
Freestanding films of reduced graphene oxide ( $\mathrm{rGO}$ ) have attracted much attention as electrodes for electrochemical capacitors, especially for flexible device applications. Here, for the first time, we report binder-free supercapacitor electrodes made of highly porous carbide-derived carbon (CDC) nanoparticles as spacers between thermally reduced graphene oxide (rGO) sheets. The addition of $\mathrm{CDC}$ between the $\mathrm{rGO}$ layers increases the wettability and accessibility of active material to the electrolyte ions, which improves electrochemical performance. The resulting electrodes exhibit high capacitance of over $210 \mathrm{~F} / \mathrm{g}$, high power densities at $100 \mathrm{mV} / \mathrm{s}$ and 10 $\mathrm{A} / \mathrm{g}$ charge/discharge rates, and long stability of over 10,000 cycles in an aqueous electrolyte. Moreover, hybrid rGO/CDC electrodes, in contrast to solely rGO-based counterparts, maintained high gravimetric capacitance as the electrode thickness increased from $5 \mu \mathrm{m}$ to $\sim 50 \mu \mathrm{m}$. This hybrid electrode material design is greatly viable in high-power energy storage devices.
\end{abstract}

\section{Keywords:}

Supercapacitors; carbide-derived carbon; graphene; nanopores; carbon composite; power density

*Corresponding author. Tel: 1-215-895-6446. E-mail: gogotsi@ drexel.edu (Yury Gogotsi)

(C) 2017. This manuscript version is made available under the Elsevier user license 


\section{Introduction}

The rapid boom in the electronics market, including wearable and portable devices, drives energy consumption and requires sustainable and portable energy storage devices [1-4]. Electrochemical capacitors (ECs), often called supercapacitors or ultracapacitors, are energy storage devices with higher power densities and faster charge/discharge times than conventional batteries [1, 5-7]. Distinct charge storage mechanisms separate ECs into two classes: electrical double layer capacitors (EDLC) and pseudocapacitors. In EDLCs, the ions adsorb onto electrodes with high specific surface areas and store charge in non-faradaic electrostatic attractions, while pseudocapacitors use fast chemical surface redox (faradaic) reactions to store charge [8]. Carbonaceous materials such as activated carbon [9], carbon black [10], carbon nanotubes $[11,12]$, carbide derived carbon (CDC) [13], and graphene $[14,15]$ are examples of electrode materials for EDLCs, whereas conducting polymers [16, 17] and transitional metals oxides [18] are examples of pseudocapacitor materials.

Graphene has been widely explored in EC applications due to its high conductivity and theoretical surface area approaching $2,600 \mathrm{~m}^{2} / \mathrm{g}[14,19]$. Due to its relatively low cost and high production volumes, reduced graphene oxide ( $\mathrm{rGO}$ ) has attracted significant attention as a graphene-based EC electrode material [14, 20, 21]. Despite their high specific surface area (SSA), the reported capacitive performance of rGO electrodes has, to date, not exceeded 130-200 $\mathrm{F} / \mathrm{g}[20,22,23]$ in aqueous electrolytes. rGO sheets inherently tend to restack during synthesis and/or electrochemical cycling and minimize the SSA that is accessible to electrolyte ions [14, 23]. To overcome this issue, zero-dimensional carbon materials such as carbon onions [24] and one-dimensional carbon materials such as CNTs were utilized as nano-spacers between graphene sheets to increase electrolyte ion accessibility [25-29]. Although this strategy had prevented

*Corresponding author. Tel: 1-215-895-6446. E-mail: gogotsi@drexel.edu (Yury Gogotsi) 
restacking, the lower capacitance of CNTs or carbon onions, as compared to graphene sheets, limits the overall capacitance of the hybrid electrodes. Moreover, until now, this strategy has mostly been demonstrated for thin film electrodes $(<10 \mu \mathrm{m})$, and the impact of nano-spacers on the performance of relatively thick binder-free graphene electrodes has not yet been systematically studied $[28,30,31]$.

Carbide-derived carbons are three-dimensional microporous carbons that can be synthesized from carbide precursors (e.g., TiC, $\mathrm{SiC}, \mathrm{MoC}$ ) by selective removal of the metal atoms from their structures using either high-temperature halogen etching $[13,32,33]$ or roomtemperature electrochemical anodization [34]. Synthesis conditions can adjust the carbide precursor type, particle size (from $20 \mathrm{~nm}$ to $300 \mu \mathrm{m}$ ) $[35,36]$, and synthesis temperature to yield highly tunable, monodisperse porosities that precisely match the corresponding electrolyte ion dimensions [13, 37]. Unlike external surface carbons, such as CNTs and carbon onions, internal surfaces of microporous CDCs offer high surface areas greater than $1,500 \mathrm{~m}^{2} / \mathrm{g}$. Furthermore, nanosized CDC particles ( $<50 \mathrm{~nm}$ in diameter) improve electrolyte transport rates and allow faster charge/discharge processes [38, 39]. Subsequently, CDCs offer high energy and high power densities as supercapacitor electrodes [40, 41]. However, to date, no attempts to integrate them as nanoscale spacers in binder-free, high-density composite freestanding films of nanoporous carbon and graphene have been reported.

Herein, for the first time, we report the high performance of freestanding EDLC hybrid electrodes that rely on CDC nanoparticles as spacers between graphene sheets. Our results demonstrate high gravimetric capacitance (> $200 \mathrm{~F} / \mathrm{g}$ ) and excellent charge retention at high voltammetry sweep rates and current loads. The electrodes yield high volumetric capacitance and

*Corresponding author. Tel: 1-215-895-6446. E-mail: gogotsi@ drexel.edu (Yury Gogotsi) 
allow rapid ion transport even when electrode thickness increases tenfold. We demonstrate different CDC loading densities to underscore the benefits of these porous nanoparticles as spacers for graphene-based energy storage composite electrodes.

\section{Materials and Methods}

\subsection{Materials:}

Graphite (SP-Carbon) and activated carbon (YP50) were used as received. Potassium permanganate $\left(\mathrm{KMnO}_{4}\right)$, sodium nitrate $\left(\mathrm{NaNO}_{3}\right)$, potassium hydroxide $(\mathrm{KOH})$, sulfuric acid $\left(\mathrm{H}_{2} \mathrm{SO}_{4}\right)$, and hydrochloric acid $(\mathrm{HCl})$ were purchased from Alfa Aesar. Hydrogen peroxide $\left(\mathrm{H}_{2} \mathrm{O}_{2}\right)$ was purchased from Sigma Aldrich. All chemicals were used as received.

Synthesis of nano-CDC: CDC particles were synthesized according to a previously described procedure $[42,43]$. Silicon carbide (SiC) nanoparticles (20 nm diameter, MTI Crystal) were loaded into a quartz furnace and treated with flowing $\mathrm{Cl}_{2}$ gas at $800{ }^{\circ} \mathrm{C}$ for 5 hours. The resulting CDC material was, subsequently, annealed with $\mathrm{H}_{2}$ gas at $600{ }^{\circ} \mathrm{C}$ for 2 hours [44].

Preparation of graphene oxide (GO): Graphite oxide was synthesized using modified Hummer's method [45]. Briefly, 2g of purified graphite powder (SP-1, Bay Carbon) and 1g of $\mathrm{NaNO}_{3}$ were added to $50 \mathrm{ml}$ of concentrated sulfuric acid under continuous stirring in an ice bath. After the temperature was brought down to $0{ }^{\circ} \mathrm{C}, 7 \mathrm{~g}$ of $\mathrm{KMnO}_{4}$ was added gradually to ensure that the reaction temperature did not exceed $10^{\circ} \mathrm{C}$. The temperature was then brought to $35^{\circ} \mathrm{C}$, and the reaction allowed to proceed for an hour before slowly being quenched with $90 \mathrm{ml}$ of deionized water $\left(\mathrm{DI} \mathrm{H}_{2} \mathrm{O}\right.$ ) while being kept below $98{ }^{\circ} \mathrm{C}$. The dark brown solution allowed to mix at $98{ }^{\circ} \mathrm{C}$ for $15 \mathrm{~min}$ before adding $280 \mathrm{ml}$ of $\mathrm{DI} \mathrm{H}_{2} \mathrm{O}$ and $7 \mathrm{ml}$ of $\mathrm{H}_{2} \mathrm{O}_{2}$. The yellowish- 
brown solution was filtered repeatedly with $\mathrm{DI} \mathrm{H}_{2} \mathrm{O}$ and further washed/centrifuged with $\mathrm{DI}_{2} \mathrm{O}$ and $1 \mathrm{M} \mathrm{HCl}$ until the $\mathrm{pH}$ of the solution was $\geq 6$ before being vacuum dried for 24 hours.

Preparation of GO-CDC composite and GO-CDC films: Aqueous dispersions of both GO (2 $\mathrm{mg} / \mathrm{ml})$ and CDC (1 $\mathrm{mg} / \mathrm{ml})$ were separately made by ultra-sonication (FB-505, Fischer Scientific, operating at $20 \mathrm{KHz}$ and 500 Watts) for 60 min using a replaceable probe (13 mm titanium tip, Qsonica). Then, the GO-CDC composite was made by adding either $10 \mathrm{wt} \%$ or 20 wt\% of the CDC solution to the GO dispersion and sonicating the composite once again for 1 hour. The resulting composite dispersion was made into a free-standing film via vacuum assisted filtration (VAF) through filter membranes (Durapore $\mathrm{CPVDF}$, Millipore) with a $0.1 \mu \mathrm{m}$ pore size. The samples were denoted according to the amount of CDC added as GOC9010 (10 wt\%) and GOC8020 (20 wt\%).

Preparation of rGO-CDC (GCDC) electrodes: GO, GOC9010, and GOC8020 films were fixed between two glass plates and subjected to thermal treatment at $200{ }^{\circ} \mathrm{C}$ for 10 hours in an oven (KSL 1100X, MTI corp.). The resulting films were denoted as rGO, GC9010, and GC8020.

\subsection{Methods:}

Electrochemical cell setup: Electrochemical tests were done in a three-electrode configuration using a Swagelok cell in which the counter electrode was activated carbon (YP50) containing 5\% wt. of polytetrafluoroethylene PTFE as a binder, and the reference electrode was $\mathrm{Ag} / \mathrm{AgCl}$ in 3.5M KCl. rGO, GC9010, and GC8020 were separately used as the working electrode. Both counter and working electrodes had $0.9 \mathrm{~cm}$ diameter. The electrolyte was potassium hydroxide

*Corresponding author. Tel: 1-215-895-6446. E-mail: gogotsi@ drexel.edu (Yury Gogotsi) 
$(6 \mathrm{M} \mathrm{KOH})$, and 2 Celgard polypropylene membranes $(0.064 \mu \mathrm{m}$ pore size and $1.2 \mathrm{~cm}$ in diameter) were used as the separator.

Electrochemical measurements: Cyclic voltammetry (CV), galvanostatic cycling (GC), and electrochemical impedance spectroscopy (EIS) measurements were done using a VMP3 potentiostat (Bio-Logic, USA).

Film characterization: Electrical conductivities were measured using four probes conductivity meter (ResTest v1, Jandel Engineering Ltd., Bedfordshire, UK) with a distance of $1 \mathrm{~mm}$ between each probe. Scanning electron microscopy (SEM) was performed on a Zeiss Supra 50VP (Carl Zeiss SMT AG, Oberkochen, Germany) equipped with an energy-dispersive spectroscope (Oxford EDS, with INCA software). X-ray diffraction (XRD) patterns were recorded with a powder diffractometer (Rigaku SmartLab) using $\mathrm{Cu} K \alpha$ radiation $\left(\lambda=1.54 \AA\right.$ ) with $0.02^{\circ} 2 \theta$ steps and $0.5 \mathrm{~s}$ dwelling time. Raman spectra were collected using Confocal Raman Spectroscopy (Renishaw inVia, UK) with He-Ne laser $(632.8 \mathrm{~nm}$ wavelength and spot size of $\sim 1 \mu \mathrm{m}$ ). X-ray photoelectron spectroscopy (XPS) survey scan were done using (Kratos AXIS $\mathrm{Ultra}^{\mathrm{DLD}}$, Manchester, U.K.) with monochromatic Al- $K_{\alpha}(1486.6 \mathrm{eV})$. Specific surface area for each film were calculated by fitting the $\mathrm{N}_{2}$ adsorption-desorption data using the BrunauerEmmett-Teller (BET) theory. Pore size distributions for each film were determined by Quenched Solid Density Functional Theory (QSDFT) slit pore fitting of the gas sorption data. These results are shown in Fig. S2.

*Corresponding author. Tel: 1-215-895-6446. E-mail: gogotsi@ drexel.edu (Yury Gogotsi) 


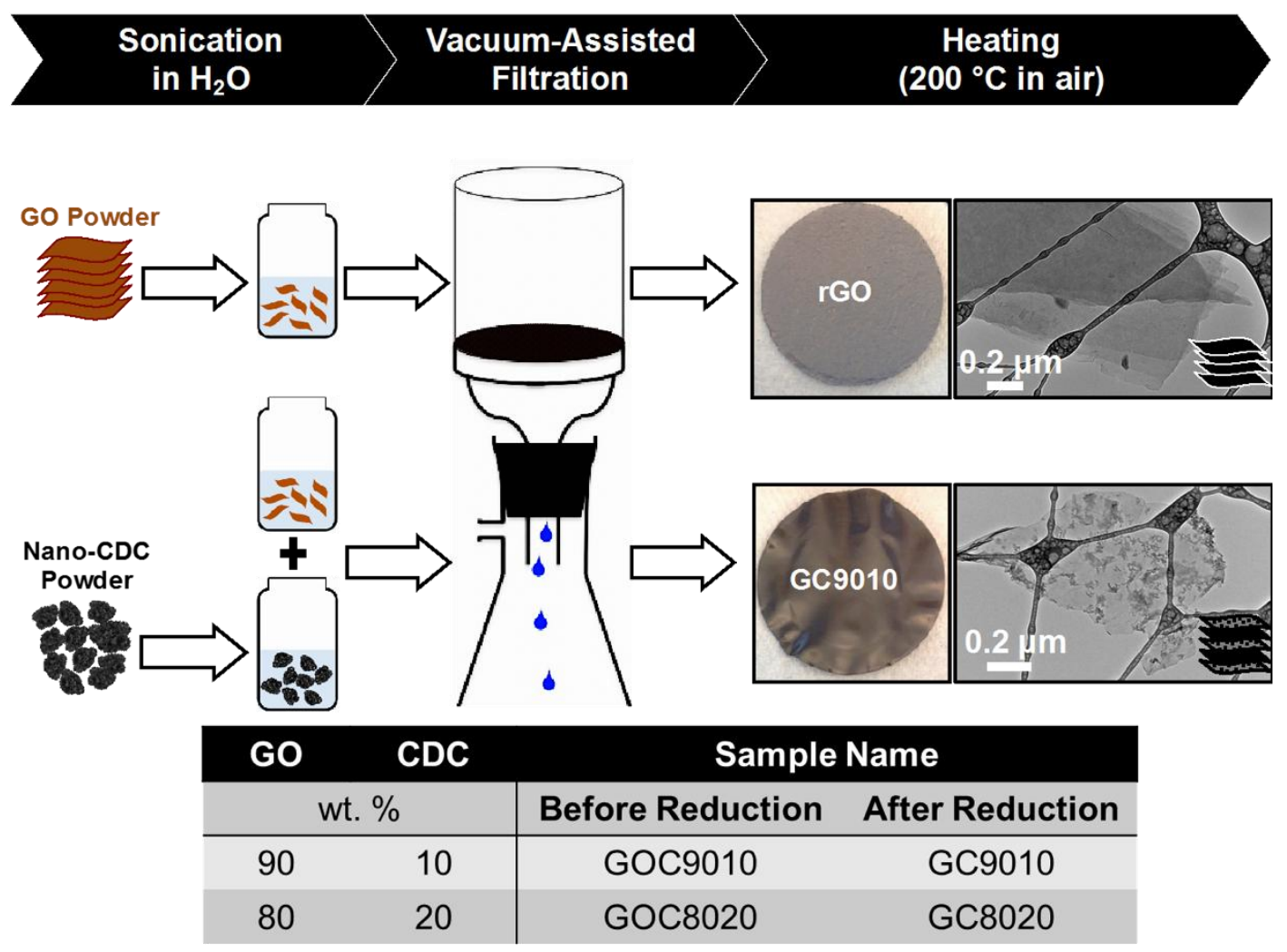

Fig. 1 Schematic of synthesis process for rGO and rGO-CDC films

\section{Results and Discussions:}

Aqueous dispersions of $\mathrm{GO}$ and $\mathrm{CDC}$ were used as precursors toward the fabrication of the $\mathrm{rGO} / \mathrm{CDC}$ composite film. A schematic of the synthesis process for film fabrication is shown in Fig. 1, in which freestanding and flexible films of GO and GOC9010 were made using VAF techniques before being thermally converted to rGO and GC9010. The electrical conductivity of rGO, GC9010, and GC8020 films are $555 \pm 10 \mathrm{~S} / \mathrm{m}, 181 \pm 8 \mathrm{~S} / \mathrm{m}$, and 166 $\pm 5 \mathrm{~S} / \mathrm{m}$ respectively. TEM images reveal that CDC particles are uniformly distributed on a sheet of graphene. The resulting structure is more accessible to ions than the sealed, stacked structure of standard collapsed rGO sheets. SEM images in Fig. 2 show how the open layered structure of GO film (Fig. 2a) became sealed as seen in Fig. 2c. The graphene sheets restacked during thermal reduction. However, the presence of interstitial CDC space-separating particles (Fig. 2b)

*Corresponding author. Tel: 1-215-895-6446. E-mail: gogotsi@ drexel.edu (Yury Gogotsi) 
prevented GO sheets from restacking even after thermal treatment (Fig 2d), making the surface

a)

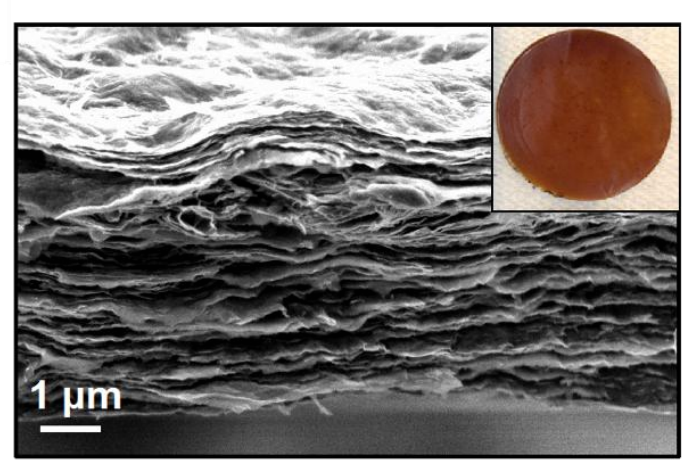

c)



b)

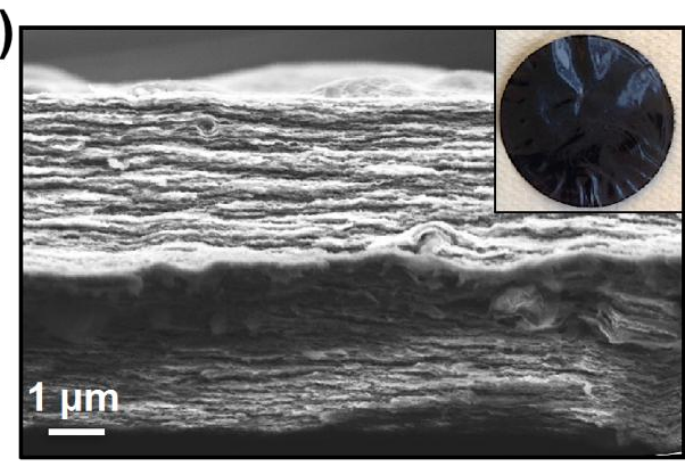

d)

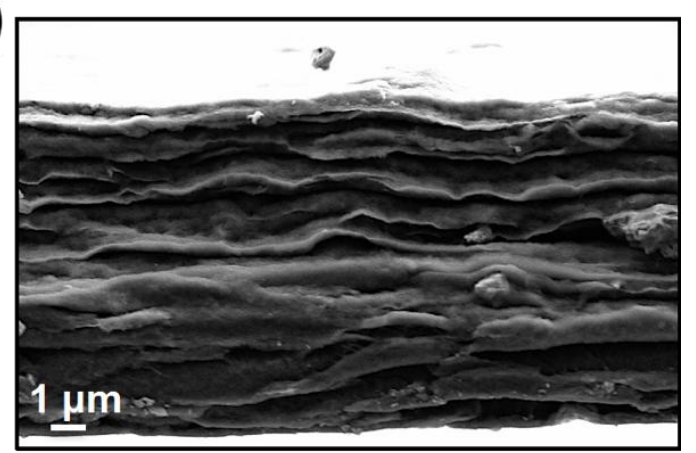

Fig 2. Cross sectional SEM images of (a) GO, (b) GOC9010, (c) rGO, and (d) GC9010 films. Insets are photos of (a) GO film and (b) GOC9010 (diameter of $4 \mathrm{~cm}$ ). area more accessible compared to rGO alone.

Raman spectra in Fig. 3a show the D and G bands of carbon, which are centered at 1330 $\mathrm{cm}^{-1}$ and $\sim 1580$, respectively. The results underscore structural changes that occur during the thermal reduction of GO to rGO. The degree of disorder in graphitic materials is measured by the intensity ratios of the $\mathrm{D}$ band to the $\mathrm{G}$ band $\left(\mathrm{I}_{\mathrm{d}} / \mathrm{I}_{\mathrm{g}}\right)$ [46], which increased as a result of GO reduction. CDC is a 3D-disordered carbon [33], and its presence has a greater influence on the $\mathrm{I}_{\mathrm{d}} / \mathrm{I}_{\mathrm{g}}$ ratio in GC8020 than in GC9010, as expected.

The (002) peaks of XRD are centered at $12^{\circ}$ (Fig. 3b) and $24^{\circ}$ (Fig. S1a) for GO film and CDC powder, respectively, which translates to interlayer spacing $\left(\mathrm{d}_{002}\right)$ of $8.1 \AA ̊$ and $3.7 \AA$ for rGO and 
a)

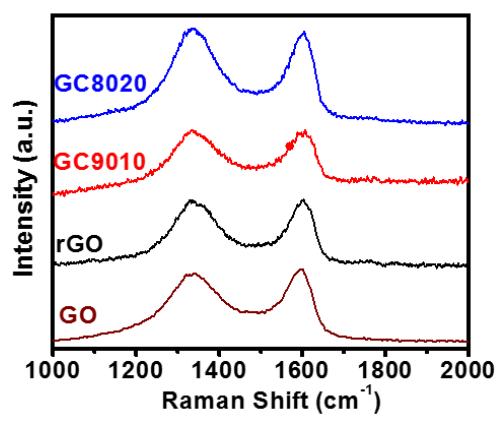

b)

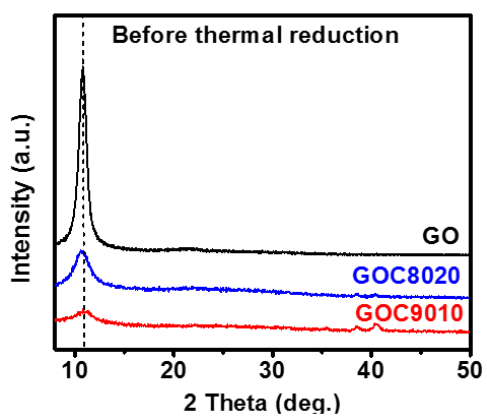

c)

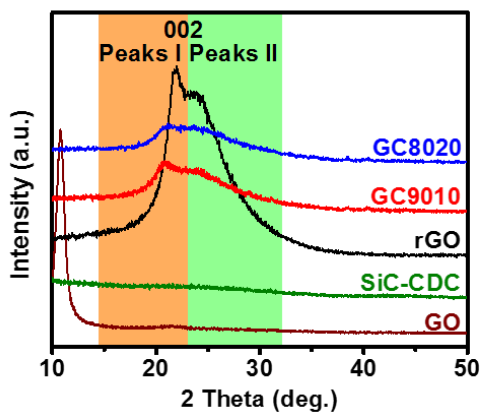

Fig 3. (a) Raman spectra of GO, rGO, GC9010, and GC8020 films. XRD patterns of (b) GO, GOC9010, and GOC9010 before thermal reduction and (c) rGO, GC9010,

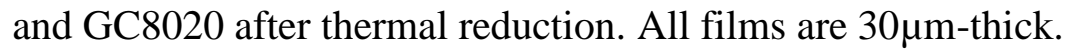

CDC respectively. No shifts in 002 peaks occurred for both GO9010 and GO8020 films; however, the peaks broadening and the decrease in their intensity (Fig. 3b) suggest that CDC is sandwiched between GO sheets. During thermal reduction of GO sheets, the (002) peak shifted to higher angles (Fig. 3c) and consisted of two peaks (I) and (II). The evolution of these peaks during thermal reductions was previously reported [47, 48], and it is attributed to partial reduction of GO and to the fast vaporization of intercalated water molecules in GO films during thermal reduction $\left(10^{\circ} \mathrm{C} / \mathrm{min}\right.$ in this case). In region (I), the broad (002) peaks shown at (20) angles of $22.0^{\circ}$ (for rGO) and $20.8^{\circ}$ (for GC9010 and GC8020) correspond to interlayer spacing $\left(\mathrm{d}_{002}\right)$ of $4.02 \AA$ and $4.26 \AA$ films respectively. However, all three films in regions (II) have the same $\mathrm{d}_{002}$ of $3.69 \AA$ A. From SEM images (Fig. 2) and XRD analysis, CDC particles are intercalated/sandwiched between rGO sheets and can act as spacers. 
The nano-CDC powder possesses high surface area $\left(\sim 1164 \mathrm{mg} / \mathrm{cm}^{2}\right)$ [43], while it's $9.5 \mathrm{mg} / \mathrm{cm}^{2}$ for rGO film as shown in Fig S.2. Hence, it's expected for GC8020 film $\left(370 \mathrm{mg} / \mathrm{cm}^{2}\right)$ to have

a)

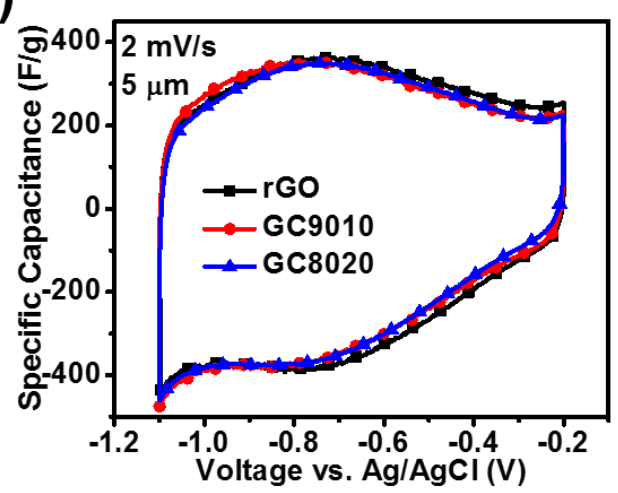

c)



b)

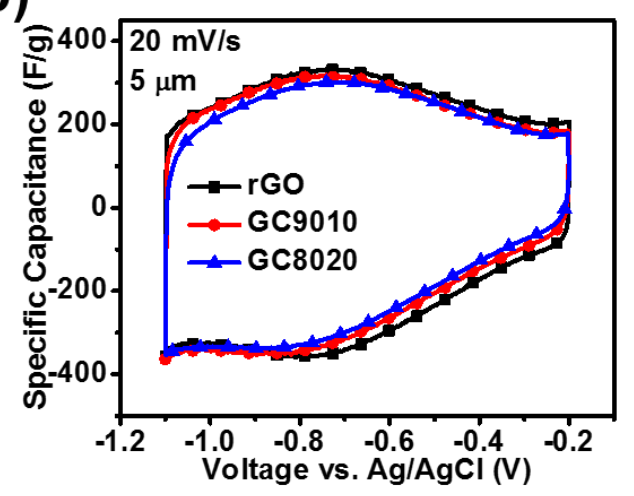

d)

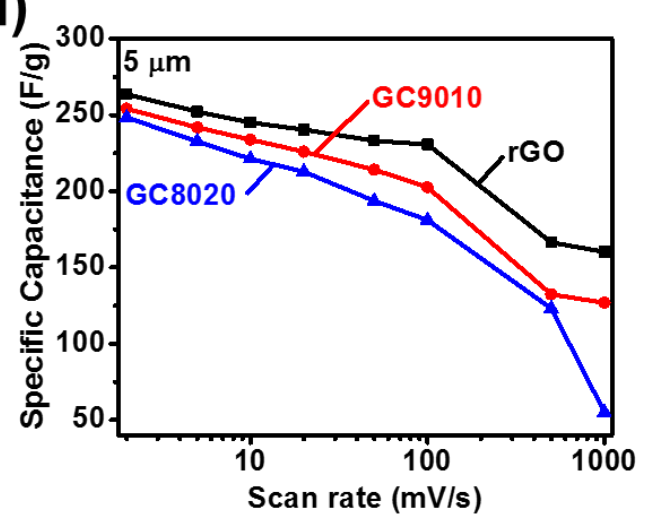

Fig 4. CV curves of rGO, GC9010, and GC8020 at (a) $2 \mathrm{mV} / \mathrm{s}$, (b) $20 \mathrm{mV} / \mathrm{s}$, and (c) $500 \mathrm{mV} / \mathrm{s}$. (d) Specific capacitance at different scan rates calculated from CV curves. higher surface area than GC9010 film $\left(18 \mathrm{mg} / \mathrm{cm}^{2}\right)$. 
a)



c)

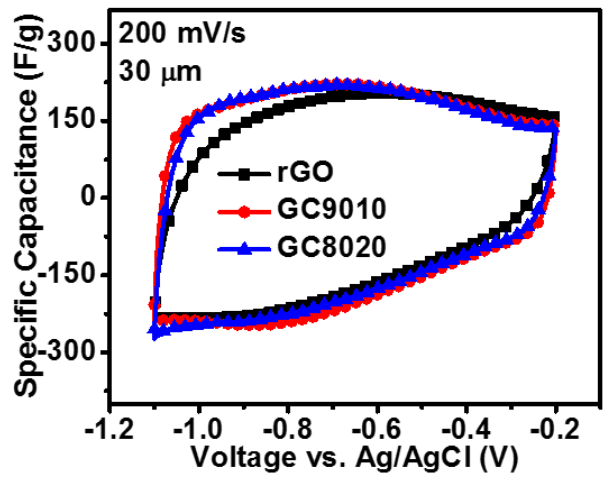

b)

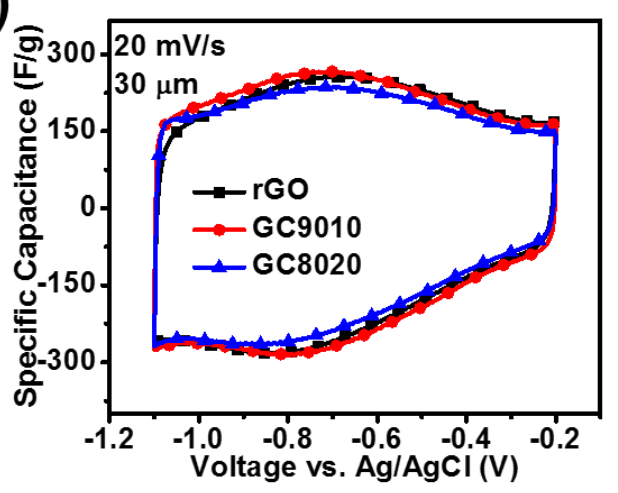

d)

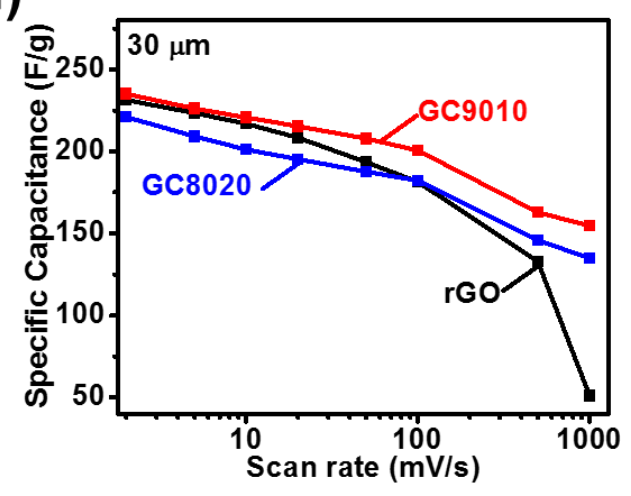

Fig 5. CV curves of rGO, GC9010, and GC8020 at (a) $2 \mathrm{mV} / \mathrm{s}$, (b) $20 \mathrm{mV} / \mathrm{s}$, and (c) $200 \mathrm{mV} / \mathrm{s}$. (d) Specific capacitance at different scan rates calculated from CV curves.

To investigate the effect of CDC spacer incorporation on the energy storage capability of rGO, we studied the electrochemical performance of all three electrodes as a function of thickness. $5 \mu$ m-thick electrodes of rGO, GC9010, and GC8020 were made and electrochemically tested at different scan rates (Fig. S3) including $2 \mathrm{mV} / \mathrm{s}$ (Fig. 4a), $20 \mathrm{mV} / \mathrm{s}$ (Fig. 4b), $500 \mathrm{mV} / \mathrm{s}$ (Fig. 4c), and $1000 \mathrm{mV} / \mathrm{s}$ (Fig. S3d). CV curves of all three electrodes exhibit a rectangular-like shape which suggests a double layer capacitive behavior. Moreover, all CVs have obvious humps between $-0.7 \mathrm{~V}$ and $-0.8 \mathrm{~V}$, which are typical features for partially reduced rGO $[14,49,50]$ as a result of pseudocapacitive contribution of oxygen containing groups on both rGO and CDC due to the fact that thermal treatment was performed in air. Table S1. Shows the content of carbon and oxygen for each film were measured by XPS (see Fig. 1Sb).

For these very thin electrodes, rGO performs slightly better than both GC9010 and GC8020 as 
shown in Fig. 4d. However, the performance of these thin electrodes (mass loading $<0.1$ 
$\mathrm{mg} / \mathrm{cm}^{2}$ ) is not comparable to the performance of much thicker commercial supercapacitor 
electrodes. It is well-known that the thickness of the electrode can have a very high impact on its 
performance [51]. To examine the effect of electrode thickness on electrochemical performance, 
we increased the electrode thicknesses to $30 \mu \mathrm{m}$. All three electrodes retained high capacitance

*Corresponding author. Tel: 1-215-895-6446. E-mail: gogotsi@ drexel.edu (Yury Gogotsi) 
and rapid ion transport (Fig. S4) and exhibited comparable capacitive performances at $2 \mathrm{mV} / \mathrm{s}$ 
(Fig. 5a) and at $20 \mathrm{mV} / \mathrm{s}$ (Fig. 5b). Interestingly, both GC9010 and GC8020 showed better high rate performance at $200 \mathrm{mV} / \mathrm{s}$ (Fig. 5c) and $1000 \mathrm{mV} / \mathrm{s}$ (Fig. S4d), while the capacitance of rGO electrodes dropped drastically at scan rates higher than $100 \mathrm{mV} / \mathrm{s}$. As shown in Fig. 5d, rGO and GC8020 have relatively similar gravimetric capacitances, about $180 \mathrm{~F} / \mathrm{g}$, at $100 \mathrm{mV} / \mathrm{s}$, whereas GC9010 has a capacitance of $200 \mathrm{~F} / \mathrm{g}$ at this high rate. When the electrode thicknesses increased to $50 \mu \mathrm{m}, \mathrm{GC} 9010$ with density of $0.932 \mathrm{~g} / \mathrm{cm}^{3}$ showed even better comparative performance at all scan rates (Fig. S5). The CVs displayed superior capacitive performance for GC9010 versus rGO at $20 \mathrm{mV} / \mathrm{s}$ (Fig. 6a). rGO showed a resistive CV curve at higher rate of $200 \mathrm{mV} / \mathrm{s}$ (Fig. 6b), while GC9010 still exhibited a standard rectangular cyclic voltammogram shape. Interestingly, GC9010 has a specific capacitance of $208 \mathrm{~F} / \mathrm{g}$ at $100 \mathrm{mV} / \mathrm{s}$ (Fig. 6c), outperforming some of

a)

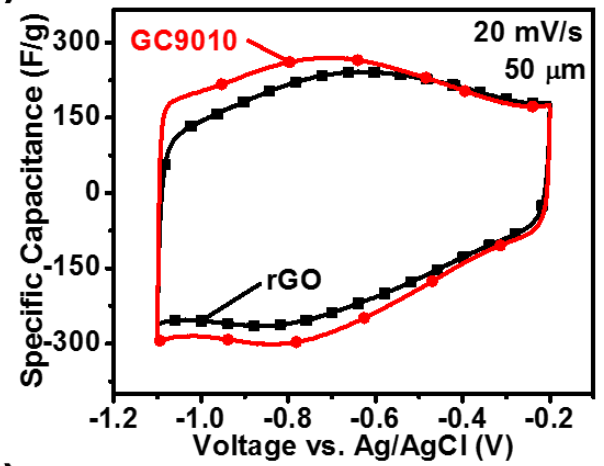

c)

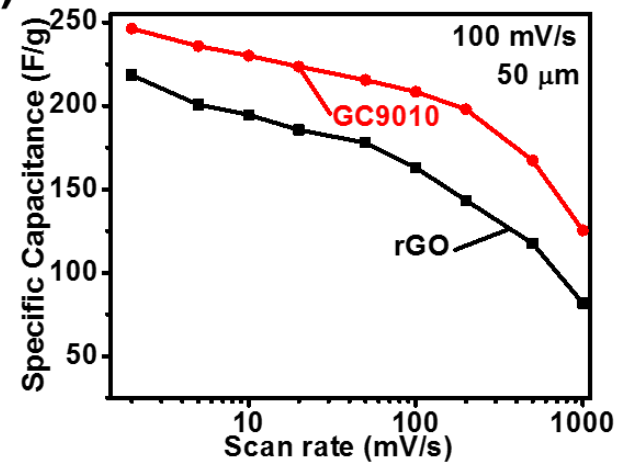

b)

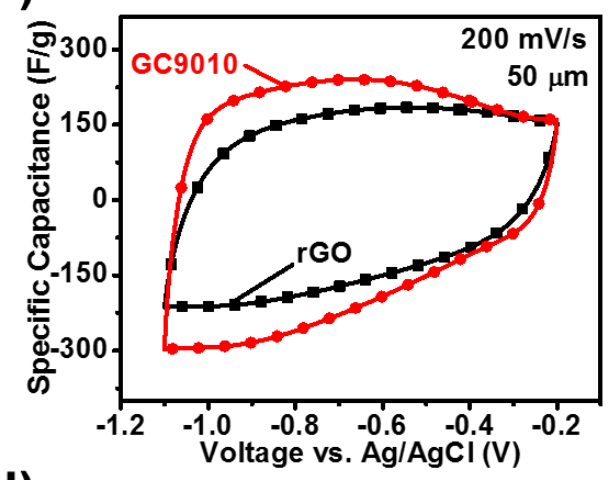

d)

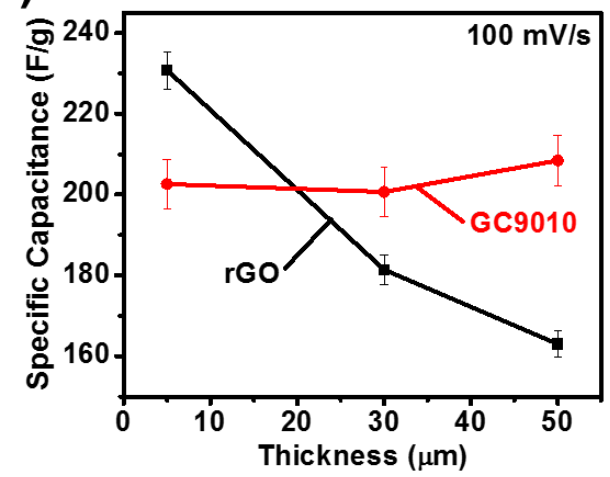

Fig 6. CV curves of rGO and GC9010 at (a) $20 \mathrm{mV} / \mathrm{s}$ and (b) $200 \mathrm{mV} / \mathrm{s}$.(c) specific capacitance of rGO and GC9010 at different scan rates calculated from CV curves and (d) specific capacitance at different electrode thickness. 
rGO-carbon composites based electrodes despite having a thickness 10 times higher (see Table S2). Moreover, a specific capacitance >200 F/g was maintained for GC9010 despite increasing electrode thickness from $5 \mu \mathrm{m}$ to $50 \mu \mathrm{m}$ as shown in Fig. 6d, while the rGO electrode was dramatically affected by such thickness variation.

Nyquist plots from electrochemical impedance spectroscopy of all $30 \mu \mathrm{m}$-thick electrodes are shown in Fig. 7a. The graphs show the typical small semicircles (charge transport
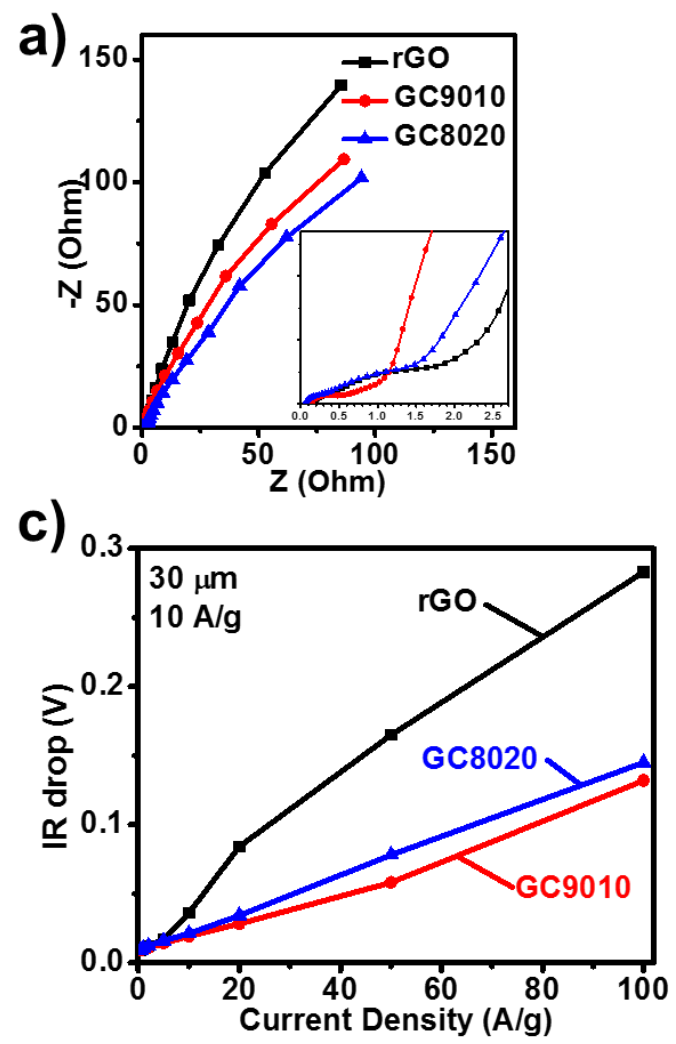

b)

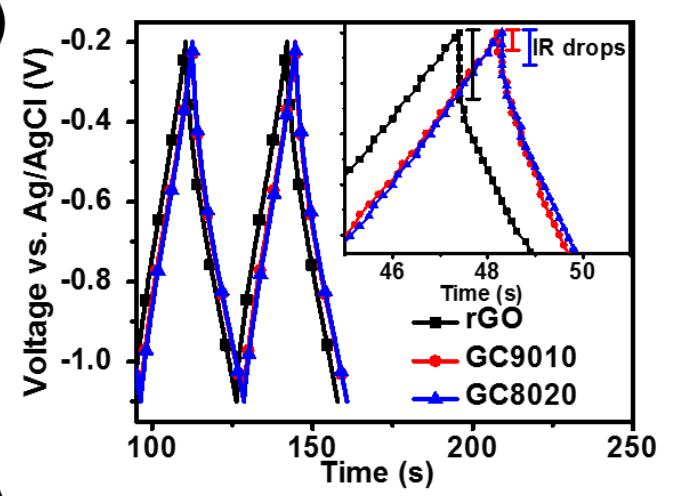

d)

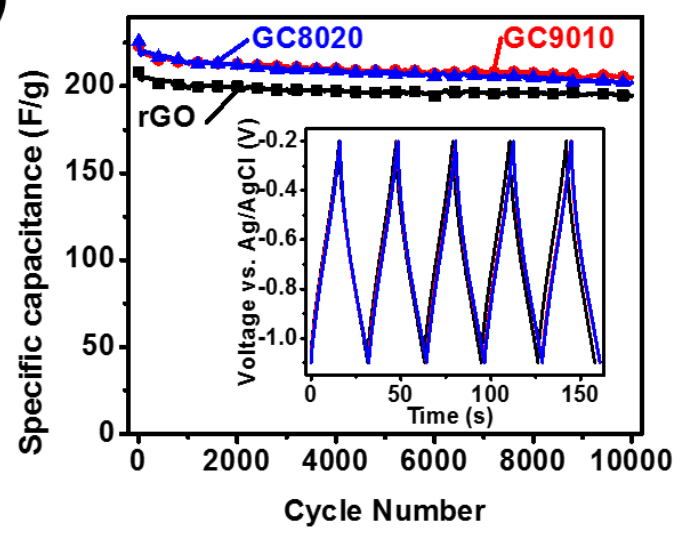

Fig 7. Electrochemical analysis of 30um thick electrodes shown by (a) Nyquist plots, (b) galvanostatic charge-discharge cycles at $10 \mathrm{~A} / \mathrm{g}$ and their internal resistance (IR) drops (inset). (c) IR drops are shown at different discharge current densities. (d) Longterm cycling performance at $10 \mathrm{~A} / \mathrm{g}$ (see inset), for 10,000 cycles, shows capacitance retention.

resistance) at low frequencies and an almost vertical line at high frequencies (ionic impedance)

[52]. In the low frequency region, rGO, GC9010, and GC8020 exhibit almost the same 
equivalent series resistance $(\mathrm{ESR})(\sim 0.1 \Omega)$, exhibited by the $\mathrm{x}$-intercept of the Nyquist plot. However, GC9010 and GC8020 demonstrate a reduced charge transfer resistance, exhibited by the size of the semicircle before the curve transitions to the $45^{\circ}$ region. Moreover, both GC9010 and GC8020 have a more vertical $45^{\circ}$ region which indicates better ion diffusion and can be attributed to the porosity of the electrode with added CDC [53]. Fig. 7b displays galvanostatic cycling between $-0.1 \mathrm{~V}$ and $-1.1 \mathrm{~V}$ at a high discharge current density of $10 \mathrm{~A} / \mathrm{g}$. Although all three electrodes possessed small IR drops, rGO has the largest IR drop which dramatically increases with increasing discharge current density in contrast to the minimal IR drops for both GC9010 and GC8020 even at $100 \mathrm{~A} / \mathrm{g}$ as seen in Fig. 7c.

Cycling performance of the three electrodes was tested for 10,000 cycles at $10 \mathrm{~A} / \mathrm{g}$ in the same voltage range shown in the inset in Fig. 7d. rGO, GC9010, and GC8020, showed 100\% columbic efficiency (Fig. S6) and specific capacity retention rates of $87 \%, 94 \%$, and $90 \%$ respectively.

\section{Conclusions}

Binder-free hybrid electrodes were made by the incorporation of porous CDC into rGO which showed excellent capacitive performance at high rates for both composites with $10 \mathrm{wt} \%$ and 20 wt $\%$ of $\mathrm{CDC}$ added. Increasing the electrode thickness from $5 \mu \mathrm{m}$ to $50 \mu \mathrm{m}$ revealed the capacity dependence of rGO on thickness, which was significantly improved when CDC was present. In fact, the sample with $10 \mathrm{wt} \%$ showed a specific capacitance larger than $200 \mathrm{~F} / \mathrm{g}$ at $100 \mathrm{mV} / \mathrm{s}$ despite changes in electrode thickness, rendering it a potential candidate in applications that require high power.

\section{Acknowledgements:}

We acknowledge Kathleen Maleski for assistance with schematic design and BET measurements, Taron Makaryan for help with Raman spectra, and Patrick Urbankowski with 
XPS. SEM and TEM characterization were done at the Central Research Facilities (CRF) at Drexel University. This work was supported as part of the Fluid Interface Reactions, Structures and Transport (FIRST) Center, an Energy Frontier Research Center funded by the U.S. Department of Energy, Office of Science, Office of Basic Energy Sciences.

\section{References:}

1. Gogotsi, Y., What Nano Can Do for Energy Storage. ACS Nano 2014, 8 (6), 5369-5371.

2. Miller, J. R.; Simon, P., Electrochemical Capacitors for Energy Management. Science 2008, 321 (5889), 651-652.

3. Simon, P.; Gogotsi, Y., Capacitive Energy Storage in Nanostructured Carbon-Electrolyte Systems. Accounts of Chemical Research 2013, 46 (5), 1094-1103.

4. Zhong, Q.; Zhong, J.; Hu, B.; Hu, Q.; Zhou, J.; Wang, Z. L., A paper-based nanogenerator as a power source and active sensor. Energy \& Environmental Science 2013, 6 (6), 1779-1784.

5. Miller, J. R.; Burke, A. F., Electrochemical capacitors: challenges and opportunities for realworld applications. The Electrochemical Society Interface 2008, 17 (1), 53.

6. Lu, M.; Beguin, F.; Frackowiak, E., Supercapacitors: materials, systems and applications. John Wiley \& Sons: 2013.

7. Frackowiak, E., Carbon materials for supercapacitor application. Phys Chem Chem Phys 2007, 9 (15), 1774-1785.

8. Beidaghi, M.; Gogotsi, Y., Capacitive energy storage in micro-scale devices: recent advances in design and fabrication of micro-supercapacitors. Energy \& Environmental Science 2014, 7 (3), 867-884.

9. Gamby, J.; Taberna, P. L.; Simon, P.; Fauvarque, J. F.; Chesneau, M., Studies and characterisations of various activated carbons used for carbon/carbon supercapacitors. J Power Sources 2001, 101 (1), 109-116.

10. Beck, F.; Dolata, M.; Grivei, E.; Probst, N., Electrochemical supercapacitors based on industrial carbon blacks in aqueous $\mathrm{H}_{2} \mathrm{SO}_{4}$. Journal of Applied Electrochemistry 31 (8), 845-853.

11. Futaba, D. N.; Hata, K.; Yamada, T.; Hiraoka, T.; Hayamizu, Y.; Kakudate, Y.; Tanaike, O.; Hatori, H.; Yumura, M.; Iijima, S., Shape-engineerable and highly densely packed single-walled carbon nanotubes and their application as super-capacitor electrodes. Nature Materials 2006, 5 (12), 987-994.

12. Xu, G. H.; Zheng, C.; Zhang, Q.; Huang, J. Q.; Zhao, M. Q.; Nie, J. Q.; Wang, X. H.; Wei, F., Binder-free activated carbon/carbon nanotube paper electrodes for use in supercapacitors. Nano Res 2011, 4 (9), 870-881.

13. Dash, R. K.; Yushin, G.; Gogotsi, Y., Synthesis, structure and porosity analysis of microporous mesoporous carbon derived from zirconium carbide. Micropor Mesopor Mat 2005, 86 (1-3), 5057.

14. Stoller, M. D.; Park, S. J.; Zhu, Y. W.; An, J. H.; Ruoff, R. S., Graphene-Based Ultracapacitors. Nano Lett 2008, 8 (10), 3498-3502.

15. Miller, J. R.; Outlaw, R. A.; Holloway, B. C., Graphene Double-Layer Capacitor with ac LineFiltering Performance. Science 2010, 329 (5999), 1637-1639.

16. Ryu, K. S.; Kim, K. M.; Park, N.-G.; Park, Y. J.; Chang, S. H., Symmetric redox supercapacitor with conducting polyaniline electrodes. J Power Sources 2002, 103 (2), 305-309. 
17. Hughes, M.; Shaffer, M. S. P.; Renouf, A. C.; Singh, C.; Chen, G. Z.; Fray, J.; Windle, A. H., Electrochemical capacitance of nanocomposite films formed by coating aligned arrays of carbon nanotubes with polypyrrole. Adv Mater 2002, 14 (5), 382-385.

18. Wu, N.-L., Nanocrystalline oxide supercapacitors. Materials Chemistry and Physics 2002, 75 (1-3), 6-11.

19. Zhu, Y.; Murali, S.; Stoller, M. D.; Ganesh, K. J.; Cai, W.; Ferreira, P. J.; Pirkle, A.; Wallace, R. M.; Cychosz, K. A.; Thommes, M.; Su, D.; Stach, E. A.; Ruoff, R. S., Carbon-Based Supercapacitors Produced by Activation of Graphene. Science 2011, 332 (6037), 1537-1541.

20. Raccichini, R.; Varzi, A.; Passerini, S.; Scrosati, B., The role of graphene for electrochemical energy storage. Nature Materials 2015, 14 (3), 271-279.

21. Sun, Y.; Wu, Q.; Shi, G., Graphene based new energy materials. Energy \& Environmental Science 2011, 4 (4), 1113-1132.

22. Wang, Y.; Shi, Z.; Huang, Y.; Ma, Y.; Wang, C.; Chen, M.; Chen, Y., Supercapacitor Devices Based on Graphene Materials. The Journal of Physical Chemistry C 2009, 113 (30), 1310313107.

23. Bonaccorso, F.; Colombo, L.; Yu, G.; Stoller, M.; Tozzini, V.; Ferrari, A. C.; Ruoff, R. S.; Pellegrini, V., Graphene, related two-dimensional crystals, and hybrid systems for energy conversion and storage. Science 2015, 347, 6217.

24. Sun, Y. Q.; Wu, Q. O.; Xu, Y. X.; Bai, H.; Li, C.; Shi, G. Q., Highly conductive and flexible mesoporous graphitic films prepared by graphitizing the composites of graphene oxide and nanodiamond. J Mater Chem 2011, 21 (20), 7154-7160.

25. Wang, Y.; Wu, Y. P.; Huang, Y.; Zhang, F.; Yang, X.; Ma, Y. F.; Chen, Y. S., Preventing Graphene Sheets from Restacking for High-Capacitance Performance. J Phys Chem C 2011, 115 (46), 23192-23197.

26. Yu, D.; Dai, L., Self-Assembled Graphene/Carbon Nanotube Hybrid Films for Supercapacitors. The Journal of Physical Chemistry Letters 2010, 1 (2), 467-470.

27. Wu, Y.; Zhang, T.; Zhang, F.; Wang, Y.; Ma, Y.; Huang, Y.; Liu, Y.; Chen, Y., In situ synthesis of graphene/single-walled carbon nanotube hybrid material by arc-discharge and its application in supercapacitors. Nano Energy 2012, 1 (6), 820-827.

28. Pham, D. T.; Lee, T. H.; Luong, D. H.; Yao, F.; Ghosh, A.; Le, V. T.; Kim, T. H.; Li, B.; Chang, J.; Lee, Y. H., Carbon Nanotube-Bridged Graphene 3D Building Blocks for Ultrafast Compact Supercapacitors. ACS Nano 2015, 9 (2), 2018-2027.

29. Fan, X. M.; Yu, C.; Yang, J.; Ling, Z.; Hu, C.; Zhang, M. D.; Qiu, J. S., A Layered-NanospaceConfinement Strategy for the Synthesis of Two-Dimensional Porous Carbon Nanosheets for High-Rate Performance Supercapacitors. Adv Energy Mater 2015, 5 (7), 1401761.

30. Yao, F.; Güneş, F.; Ta, H. Q.; Lee, S. M.; Chae, S. J.; Sheem, K. Y.; Cojocaru, C. S.; Xie, S. S.; Lee, Y. H., Diffusion Mechanism of Lithium Ion through Basal Plane of Layered Graphene. Journal of the American Chemical Society 2012, 134 (20), 8646-8654.

31. He, X. J.; Wang, J. X.; Xu, G. H.; Yu, M. X.; Wu, M. B., Synthesis of microporous carbon/graphene composites for high-performance supercapacitors. Diam Relat Mater 2016, 66, 119-125.

32. Yushin, G. N.; Hoffman, E. N.; Nikitin, A.; Ye, H. H.; Barsoum, M. W.; Gogotsi, Y., Synthesis of nanoporous carbide-derived carbon by chlorination of titanium silicon carbide. Carbon 2005, 43 (10), 2075-2082.

33. Presser, V.; Heon, M.; Gogotsi, Y., Carbide-Derived Carbons - From Porous Networks to Nanotubes and Graphene. Advanced Functional Materials 2011, 21 (5), 810-833. 
34. Lukatskaya, M. R.; Halim, J.; Dyatkin, B.; Naguib, M.; Buranova, Y. S.; Barsoum, M. W.; Gogotsi, Y., Room-Temperature Carbide-Derived Carbon Synthesis by Electrochemical Etching of MAX Phases. Angewandte Chemie International Edition 2014, 53 (19), 4877-4880.

35. Perez, C. R.; Yeon, S. H.; Segalini, J.; Presser, V.; Taberna, P. L.; Simon, P.; Gogotsi, Y., Structure and Electrochemical Performance of Carbide-Derived Carbon Nanopowders. Advanced Functional Materials 2013, 23 (8), 1081-1089.

36. Dyatkin, B.; Gogotsi, O.; Malinovskiy, B.; Zozulya, Y.; Simon, P.; Gogotsi, Y., High capacitance of coarse-grained carbide derived carbon electrodes. J Power Sources 2016, 306, 32-41.

37. Lin, R.; Huang, P.; Segalini, J.; Largeot, C.; Taberna, P. L.; Chmiola, J.; Gogotsi, Y.; Simon, P., Solvent effect on the ion adsorption from ionic liquid electrolyte into sub-nanometer carbon pores. Electrochim Acta 2009, 54 (27), 7025-7032.

38. Portet, C.; Yushin, G.; Gogotsi, Y., Effect of carbon particle size on electrochemical performance of EDLC. Journal of The Electrochemical Society 2008, 155 (7), A531-A536.

39. Chmiola, J.; Largeot, C.; Taberna, P. L.; Simon, P.; Gogotsi, Y., Desolvation of ions in subnanometer pores and its effect on capacitance and double-layer theory. Angew Chem Int Edit 2008, 47 (18), 3392-3395.

40. Presser, V.; Zhang, L. F.; Niu, J. J.; McDonough, J.; Perez, C.; Fong, H.; Gogotsi, Y., Flexible Nano-felts of Carbide-Derived Carbon with Ultra-high Power Handling Capability. Adv Energy Mater 2011, 1 (3), 423-430.

41. Tsai, W. Y.; Gao, P. C.; Daffos, B.; Taberna, P. L.; Perez, C. R.; Gogotsi, Y.; Favier, F.; Simon, P., Ordered mesoporous silicon carbide-derived carbon for high-power supercapacitors. Electrochem Commun 2013, 34, 109-112.

42. Gogotsi, Y.; Nikitin, A.; Ye, H. H.; Zhou, W.; Fischer, J. E.; Yi, B.; Foley, H. C.; Barsoum, M. W., Nanoporous carbide-derived carbon with tunable pore size. Nature Materials 2003, 2 (9), 591-594.

43. Dyatkin, B.; Zhang, Y.; Mamontov, E.; Kolesnikov, A. I.; Cheng, Y. Q.; Meyer, H. M.; Cummings, P. T.; Gogotsi, Y., Influence of Surface Oxidation on Ion Dynamics and Capacitance in Porous and Nonporous Carbon Electrodes. J Phys Chem C 2016, 120 (16), 8730-8741.

44. Dyatkin, B.; Gogotsi, Y., Effects of structural disorder and surface chemistry on electric conductivity and capacitance of porous carbon electrodes. Faraday Discuss 2014, 172, 139-162.

45. Hummers, W. S.; Offeman, R. E., Preparation of Graphitic Oxide. Journal of the American Chemical Society 1958, 80 (6), 1339-1339.

46. Ferrari, A. C.; Robertson, J., Interpretation of Raman spectra of disordered and amorphous carbon. Physical Review B 2000, 61 (20), 14095-14107.

47. Huh, S. H., Thermal reduction of graphene oxide. INTECH Open Access Publisher: 2011.

48. Jeong, H.-K.; Lee, Y. P.; Jin, M. H.; Kim, E. S.; Bae, J. J.; Lee, Y. H., Thermal stability of graphite oxide. Chemical Physics Letters 2009, 470 (4-6), 255-258.

49. Oh, Y. J.; Yoo, J. J.; Kim, Y. I.; Yoon, J. K.; Yoon, H. N.; Kim, J. H.; Park, S. B., Oxygen functional groups and electrochemical capacitive behavior of incompletely reduced graphene oxides as a thin-film electrode of supercapacitor. Electrochim Acta 2014, 116, 118-128.

50. Xu, B.; Yue, S.; Sui, Z.; Zhang, X.; Hou, S.; Cao, G.; Yang, Y., What is the choice for supercapacitors: graphene or graphene oxide? Energy \& Environmental Science 2011, 4 (8), 2826-2830.

*Corresponding author. Tel: 1-215-895-6446. E-mail: gogotsi@ drexel.edu (Yury Gogotsi) 
51. Gogotsi, Y.; Simon, P., True Performance Metrics in Electrochemical Energy Storage. Science 2011, 334 (6058), 917-918.

52. Conway, B. E., Electrochemical supercapacitors: scientific fundamentals and technological applications. Springer Science \& Business Media: 2013.

53. Taberna, P. L.; Simon, P.; Fauvarque, J. F., Electrochemical characteristics and impedance spectroscopy studies of carbon-carbon supercapacitors. Journal of the Electrochemical Society 2003, 150 (3), A292-A300.

*Corresponding author. Tel: 1-215-895-6446. E-mail: gogotsi@drexel.edu (Yury Gogotsi) 


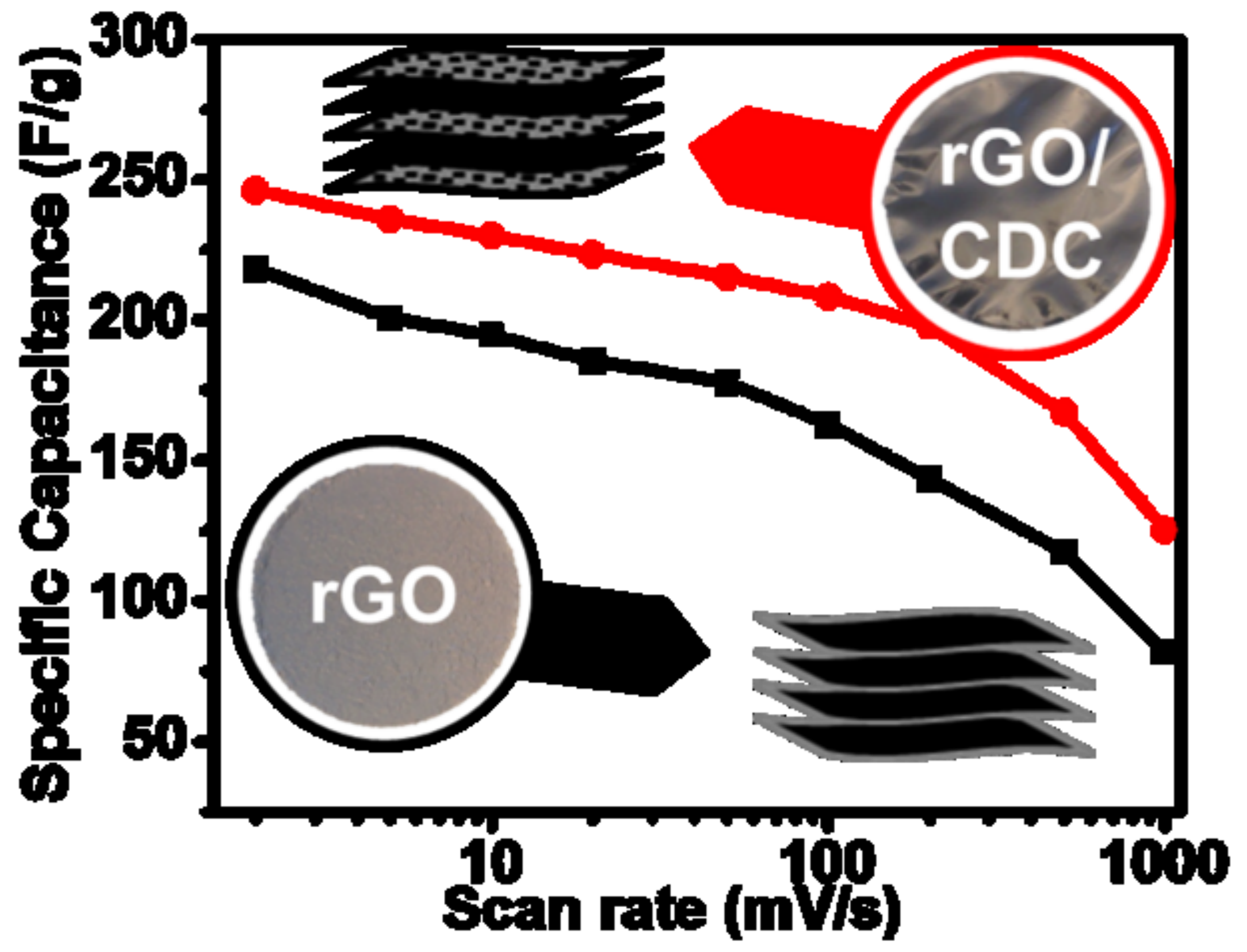

